\title{
Computational Optimization of Manufacturing Batch Size and Shipment for an Integrated EPQ Model with Scrap
}

\author{
Yuan-Shyi Peter Chiu ${ }^{1}$, Hong-Dar Lin ${ }^{1}$, Ming-Hon Hwang ${ }^{2} *$, Nong Pan ${ }^{3}$ \\ ${ }^{1}$ Department of Industrial Engineering \& Management, Chaoyang University of Technology, Taichung, Chinese Taipei \\ ${ }^{2}$ Department of Marketing and Logistics Management, Chaoyang University of Technology, Taichung, Chinese Taipei \\ ${ }^{3}$ Department of Business Administration, Chaoyang University of Technology, Taichung, Chinese Taipei \\ E-mail: "hwangmh@cyut.edu.tw
}

Received March 12, 2011; revised April 2, 2011; accepted April 28, 2011

\begin{abstract}
This paper employs mathematical modeling and algebraic approach to derive the optimal manufacturing batch size and number of shipment for a vendor-buyer integrated economic production quantity (EPQ) model with scrap. Unlike the conventional method by using differential calculus to determine replenishment lot size and optimal number of shipments for such an integrated system, this paper proposes a straightforward algebraic approach to replace the use of calculus on the total cost function for solving the optimal productionshipment policies. A simpler form for computing long-run average cost for such a vendor-buyer integrated EPQ problem is also provided.
\end{abstract}

Keywords: Computational Optimization, Manufacturing Batch Size, Shipments, EPQ Model, Random Scrap Rate, Algebraic Approach

\section{Introduction}

The economic production quantity (EPQ) model was first introduced by Taft [1] to assist practitioners in production and inventory control field to determine the economic replenishment batch size that minimizes total production-inventory costs. Classic economic production quantity model assumes a continuous inventory issuing policy for satisfying customer's demand. However, in real world vendor- buyer system, multiple or periodic deliveries of finished products are often adopted. Therefore, "how many shipments should a manufacturing lot be broken down to?” becomes another critical issue that practitioners must address in order to minimize overall production-inventory-delivery costs.

Studies related to various aspects of supply chain optimization have been extensively carried out (see for example [2-9]) in past decades. Goyal [2] examined an integrated single supplier-single customer problem. He proposed a method that is typically applicable to those inventory problems where a product is procured by a single customer from a single supplier. Example was provided to demonstrate his proposed model. Schwarz et al. [3] considered the system fill-rate of a one-warehouse $\mathrm{N}$-identical retailer distribution system as a function of warehouse and retailer safety stock. They used an approximation model from a prior study to maximize system fill-rate subject to a constraint on system safety stock. As results, properties of fill-rate policy lines are suggested. They may be used to provide managerial insight into system optimization and as the basis for heuristics. Lu [4] studied a one-vendor multi-buyer integrated inventory model with the objective of minimizing vendor's total annual cost subject to the maximum costs that the buyers may be prepared to incur. Lu's model required to know buyer's annual demand and previous order frequency. As a result, an optimal solution for the onevendor one-buyer case was obtained and a heuristic approach for the one-vendor multi-buyer case was also provided. Sarker and Khan [5] considered a production system that procures raw materials from suppliers in a lot and processes them into finished products which are then delivered to outside buyers at fixed points in time. A general cost model was formulated considering both raw materials and finished products. Using this model, a simple procedure was developed to determine the optimal 
ordering policy for raw materials as well as the manufacturing batch size, so that the overall costs for such a supply chain system can be minimized. Chiu et al. [9] incorporated a multi-delivery policy and quality assurance into an imperfect economic production quantity (EPQ) model with scrap and rework. They assumed that the random defective items produced are partially repairable and are reworked in each cycle when regular production ends, and the finished items can only be delivered to customers if the whole lot is quality assured at the end of rework. Fixed quantity multiple installments of the finished batch are delivered to customers at a fixed interval of time. The expected integrated cost function per unit time was derived. A closed-form optimal batch size solution to the problem was obtained.

Imperfect quality items produced in real world manufacturing environments is another inevitable and important issue that practitioners in the production management filed must deal with. In the past decades, many studies have been carried out to address the issue of defective items in the production lines (see for example [10-14]). The nonconforming items sometimes can be repaired through rework, hence overall production costs can be significantly reduced [15-20]. Yu and Bricker [15] presented an informative application of Markov Chain analysis to a multistage manufacturing problem. Jamal et al. [16] studied the optimal manufacturing batch size with rework process at a single-stage production system. Cases of rework being completed within the same production cycle, and rework being done after $\mathrm{N}$ cycles are examined. They developed mathematical models for each case and derived total system costs and optimal batch sizes accordingly. Chiu et al. [19] proposed a numerical method for expediting scrap-or-rework decision making in EPQ model with failure in repair.

Algebraic approach for determining economic order quantity (EOQ) model with backlogging was introduced by Grubbström and Erdem [21]. They proposed algebraic derivations to solve the optimal order quantity without reference to the first-order or second-order differentiations. Various aspects of supply chain optimization studies have employed the same or similar methodologies $[22,23]$. This paper uses mathematical modeling to derive the long-run average cost function for the proposed vendor-buyer integrated EPQ model with scrap; then employs such a straightforward algebraic derivation to determine the optimal production-shipment policies for the proposed EPQ model.

\section{The Proposed Model and Mathematical Modeling}

The proposed economic production quantity model as- sumes there is an $x$ portion of defective items produced randomly at a production rate $d$ during regular production time. All produced items are screened and inspection cost per item is included in the unit production cost $C$. All nonconforming items are assumed to be scrap and will be discarded at the end of production. Under regular supply (not allowing shortages), the constant production rate $P$ must be larger than the sum of demand rate $\lambda$ and production rate of scrap items $d$. That is: $(P-d-\lambda)>0$. The production rate of scrap items $d$ can be expressed as $d=P x$.

A multi-delivery policy is considered in this study and it is also assumed that the finished items can only be delivered to customers if the whole lot is quality assured at the end of production process. Fixed-quantity $n$ installments of finished batch are delivered to customers at a fixed interval of time during the production downtime $t_{2}$ (see Figure 1). Additional notation is listed in Nomenclature in Appendix.

$T C(Q, n)$, the total production-inventory-delivery costs per cycle consists of 1) setup cost; 2) variable production costs; 3) variable scrap disposal costs; 4) fixed delivery cost; 5) variable delivery costs; 6) variable holding costs at the supplier side for all items produced (defective and perfect quality items) in $t_{1}$ and all items waiting to be delivered in $t_{2}$; and 7) holding cost for finished goods stocked at customer's end. Therefore, $\operatorname{TC}(Q, n)$ is

$$
\begin{aligned}
& T C(Q, n) \\
= & K+C Q+C_{S}[x Q]+n K_{1}+C_{T}[Q(1-x)] \\
& +h\left[\frac{H+d t_{1}}{2}\left(t_{1}\right)+\left(\frac{n-1}{2 n}\right) H t_{2}\right] \\
& +\frac{h_{2}}{2}\left[\frac{H}{n} t_{2}+T\left(H-\lambda t_{2}\right)\right]
\end{aligned}
$$

Figure 2 shows supplier's inventory holding during delivery time $t_{2}$. The variable holding costs for finished products kept by the supplier in delivery time $t_{2}$ are

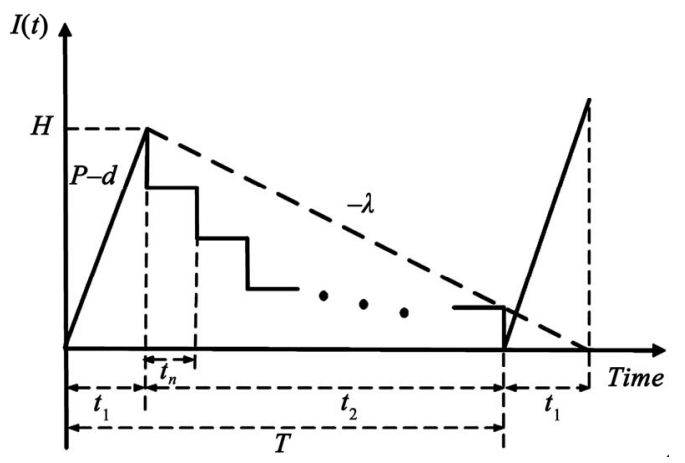

Figure 1. On-hand inventory of perfect quality items in the proposed EPQ model with scrap and a multiple shipment policy. 
1) When $n=1$, total holding cost in delivery time $=0$.

2) When $n=2$, total holding costs in delivery time become (see Figure 2)

$$
h\left(\frac{H}{2} \times \frac{t_{2}}{2}\right)=h\left(\frac{1}{2^{2}}\right) H t_{2}
$$

3) When $n=3$, total holding costs in delivery time are

$$
h\left(\frac{2 H}{3} \times \frac{t_{2}}{3}+\frac{1 H}{3} \times \frac{t_{2}}{3}\right)=h\left(\frac{2+1}{3^{2}}\right) H t_{2}
$$

4) When $n=4$, total holding costs in delivery time become

$$
h\left(\frac{3 H}{4} \times \frac{t_{2}}{4}+\frac{2 H}{4} \times \frac{t_{2}}{4}+\frac{1 H}{4} \times \frac{t_{2}}{4}\right)=h\left(\frac{3+2+1}{4^{2}}\right) H t_{2}(4)
$$

Therefore, the following general term for total holding costs during $t_{2}$ can be obtained (as shown in Equation (1) above):

$h\left(\frac{1}{n^{2}}\right)\left(\sum_{i=1}^{n-1} i\right) H t_{2}=h\left(\frac{1}{n^{2}}\right)\left[\frac{n(n-1)}{2}\right] H t_{2}=h\left(\frac{n-1}{2 n}\right) H t_{2}$

Taking randomness of scrap rate into consideration and employing the expected values of it, and with further derivations, the long-run average costs per unit time for the proposed EPQ model, $\mathrm{E}[T C U(Q, n)]$ can be derived as follows (refer to a similar derivation procedure in [9]):

$$
\begin{aligned}
& E[T C U(Q, n)] \\
= & \frac{E[T C(Q, n)]}{E[T]} \\
= & \frac{C \lambda}{1-E[x]}+\frac{\left(K+n K_{1}\right) \lambda}{Q(1-E[x])}+\frac{C_{S} E[x] \lambda}{(1-E[x])}+C_{T} \lambda \\
& +\frac{h Q \lambda}{2 P(1-E[x])}+\left(\frac{n-1}{n}\right)\left[\frac{h Q(1-E[x])}{2}-\frac{h Q \lambda}{2 P}\right] \\
& +\frac{h_{2} Q}{2}\left[\left(\frac{1}{n}\right)(1-E[x])+\left(\frac{n-1}{n}\right) \frac{\lambda}{P}\right]
\end{aligned}
$$

\section{Deriving Optimal Production-Shipment Policies without Derivatives}

This study employs algebraic approach to derive the optimal production-shipment policies, instead of using differential calculus on $\operatorname{E}[T C U(Q, n)]$ with the need of proving its optimality [21-23]. In Equation (6), both $Q$ and $n$ are decision variables, by rearranging terms in Equation (6) as the constants, $Q^{-1}, Q, n Q^{-1}$, and $Q n^{-1}$, one has

$$
\begin{aligned}
E[\operatorname{TCU}(Q, n)] & =\beta_{1}+\beta_{2}(Q)+\beta_{3}\left(Q^{-1}\right) \\
& +\beta_{4}\left(n Q^{-1}\right)+\beta_{5}\left(n^{-1} Q\right)
\end{aligned}
$$

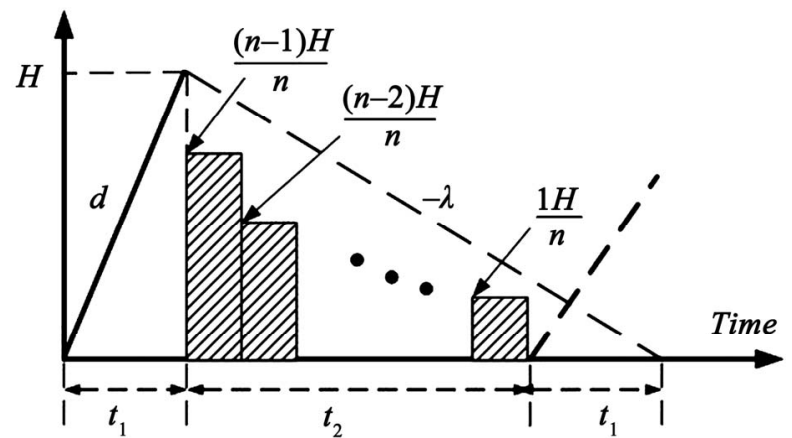

Figure 2. On-hand inventory of the finished items kept by supplier during $t_{2}$ in the proposed EPQ model.

where $\beta_{1}, \beta_{2}, \beta_{3}, \beta_{4}$, and $\beta_{5}$ denote the following:

$$
\begin{aligned}
& \beta_{1}=\frac{C \lambda}{1-E[x]}+\frac{C_{S} E[x] \lambda}{(1-E[x])}+C_{T} \lambda \\
& \beta_{2}=+\left\{\frac{h \lambda}{2 P(1-E[x])}+\frac{h(1-E[x])}{2}-\frac{\lambda}{2 P}\left(h-h_{2}\right)\right\}
\end{aligned}
$$

$$
\begin{aligned}
& \beta_{3}=+\frac{K \lambda}{(1-E[x])} \\
& \beta_{4}=+\frac{K_{1} \lambda}{(1-E[x])} \\
& \beta_{5}=+\left\{\left[\frac{\lambda}{2 P}-\frac{(1-E[x])}{2}\right]\left(h-h_{2}\right)\right\}
\end{aligned}
$$

With further rearrangements, Equation (7) becomes

$$
\begin{aligned}
& E[T C U(Q, n)]=\beta_{1}+Q^{-1}\left[\beta_{2} \cdot Q^{2}+\beta_{3}\right] \\
& +\left(n^{-1} Q\right)\left[\beta_{4}\left(n Q^{-1}\right)^{2}+\beta_{5}\right] \\
& E[\operatorname{TCU}(Q, n)] \\
& =\beta_{1}+Q^{-}\left[\left(\sqrt{\beta_{2}} \cdot Q\right)^{2}+\left(\sqrt{\beta_{3}}\right)^{2}-2\left(\sqrt{\beta_{2}} \cdot Q\right)\left(\sqrt{\beta_{3}}\right)\right] \\
& +\left(n^{-1} Q\right)\left[\left(\sqrt{\beta_{4}}\left(n Q^{-1}\right)\right)^{2}+\left(\sqrt{\beta_{5}}\right)^{2}-2 \sqrt{\beta_{4}} \sqrt{\beta_{5}}\left(n Q^{-1}\right)\right] \\
& +Q^{-1}\left[2\left(\sqrt{\beta_{2}} \cdot Q\right)\left(\sqrt{\beta_{3}}\right)\right]+\left(n^{-1} Q\right)\left[2 \sqrt{\beta_{4}} \sqrt{\beta_{5}}\left(n Q^{-1}\right)\right] \\
& E[T C U(Q, n)]=\beta_{1}+Q^{-1}\left[\left(\sqrt{\beta_{2}} \cdot Q\right)-\sqrt{\beta_{3}}\right]^{2} \\
& +\left(n^{-1} Q\right)\left[\left(n Q^{-1} \sqrt{\beta_{4}}\right)-\sqrt{\beta_{5}}\right]^{2} \\
& +2 \sqrt{\beta_{2} \cdot \beta_{3}}+2 \sqrt{\beta_{4} \cdot \beta_{5}}
\end{aligned}
$$


It is noted that if the following square terms (Equations (17) and (18)) equal zero, then Equation (15) will be minimized:

$$
\begin{gathered}
Q^{-1}\left[\left(\sqrt{\beta_{2}} \cdot Q\right)-\sqrt{\beta_{3}}\right]^{2}=0 \\
\left(n^{-1} Q\right)\left[\left(n Q^{-1} \sqrt{\beta_{4}}\right)-\sqrt{\beta_{5}}\right]^{2}=0
\end{gathered}
$$

or

$$
Q^{*}=\sqrt{\frac{\beta_{3}}{\beta_{2}}}
$$

and

$$
n^{*}=\sqrt{\frac{\beta_{5}}{\beta_{4}}} \cdot Q^{*}
$$

Substituting Equations (9) and (10) in Equation (18), the optimal replenishment lot size $Q^{*}$ can be obtains:

$$
Q^{*}=\sqrt{\frac{2 K \lambda}{\frac{h \lambda}{P}+h(1-E[x])^{2}-\frac{\lambda}{P}\left(h-h_{2}\right)(1-E[x])}}
$$

Substituting Equations (11), (12), and (20) in Equation (19), the optimal number of shipments is

$$
n^{*}=\sqrt{\frac{K\left(h-h_{2}\right)(1-E[x])\left[\frac{\lambda}{P}-(1-E[x])\right]}{K_{1}\left\{\frac{h \lambda}{P}+h(1-E[x])^{2}-\frac{\lambda}{P}\left(h-h_{2}\right)(1-E[x])\right\}}}
$$

One notes that Equation (21) is identical to what was obtained by using the conventional differential calculus method on $E[T C U(Q, n)]$ [24]. Further, from Equation (7) the optimal cost function $\operatorname{E}\left[\operatorname{TCU}\left(Q^{*}, n^{*}\right)\right]$ is

$$
E\left[\operatorname{TCU}\left(Q^{*}, n^{*}\right)\right]=\beta_{1}+2 \sqrt{\beta_{2} \cdot \beta_{3}}+2 \sqrt{\beta_{4} \cdot \beta_{5}}
$$

\section{Demonstrative Example}

Consider a product can be produced at an annual rate of 60,000 units and this item has experienced a flat demand rate of 3,400 units per year. Assume that during production process a random scrap rate which follows a uniform distribution over the interval [0, 0.3]. In additions, the following values of related variables are considered:

$C=\$ 100$ per item,

$C_{S}=\$ 20$, disposal cost per scrap item,

$h=\$ 20$ per item per year,

$h_{2}=\$ 80$ per item kept at the customer's end per unit time,

$K=\$ 20,000$ per production run,

$K_{1}=\$ 4350$ per shipment, a fixed cost,

$C_{T}=\$ 0.1$ per item delivered.

From Equations (21), one obtains the optimal number of delivery $n^{*}=3$. By plugging $n^{*}$ back into Equation (7) and resolving the algebraic solution for $Q^{*}$ one finds the optimal production batch size $Q^{*}=2652$. Calculating Equation (22) one obtains the long-run average cost $\mathrm{E} \times$ $\left[\operatorname{TCU}\left(Q^{*}, n^{*}\right)\right]=\$ 512,047$. Figure 3 shows the convexity of the long-run integrated cost function $\mathrm{E}\left[\operatorname{TCU}\left(Q, n^{*}=\right.\right.$ 3)].

It is noted that $n^{*}$ should practically be an integer number, but Equation (21) gives a real number. In order to obtain the optimal integer value of $n$, one should compute the $\mathrm{E}[T C U(Q, n)]$ for both integers that are adjacent to real number $n^{*}$ respectively (for instance, in this example Equation (21) gives $n^{*}=3.1733$, so both $n=3$ and $n=4$ must be plugged in $\mathrm{E}[T C U(Q, n)])$, and select the one with minimum cost as our optimal $n^{*}$.

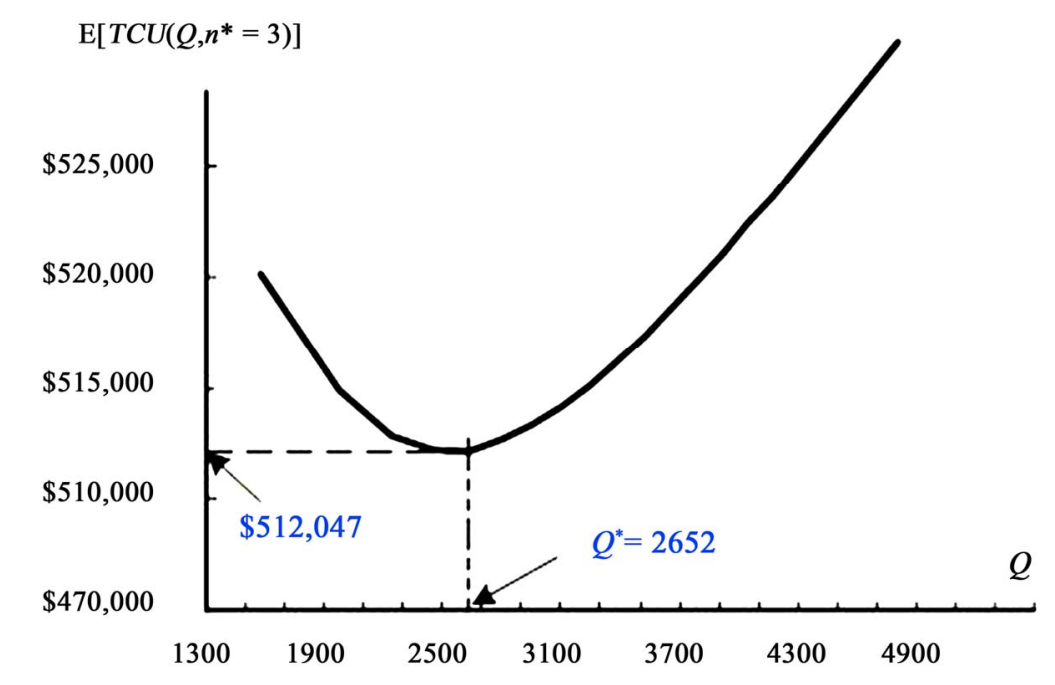

Figure 3. Convexity of the long-run integrated cost function $\operatorname{E}\left[\operatorname{TCU}\left(Q, n^{*}=3\right)\right]$. 


\section{Conclusions}

This paper derives the optimal manufacturing batch size and number of shipment for a vendor-buyer integrated EPQ model with scrap using mathematical modeling and algebraic approach. It is confirmed the research results from the proposed algebraic derivations are identical to what were derived by the use of conventional differential calculus. In additions, this study also reveals a simpler computation formula (i.e. Equation (22)) for the long-run average cost function for such a vendor-buyer integrated EPQ problem. This straightforward algebraic approach enables practitioners or students who with little or no knowledge of calculus to learn or handle with ease the real-life EPQ model.

\section{Acknowledgements}

The authors greatly appreciate the National Science Council of Taiwan for supporting this research under grant number: NSC 99-2221-E-324-017.

\section{References}

[1] E. W. Taft, “The Most Economical Production Lot,” Iron Age, Vol. 101, 1918, pp. 1410-1412.

[2] S. K. Goyal, "Integrated Inventory Model for a Single Supplier-Single Customer Problem,” International Journal of Production Research, Vol. 15, No. 1, 1977, pp. 107-111.

[3] L. B. Schwarz, B. L. Deuermeyer and R. D. Badinelli, "Fill-Rate Optimization in a One-Warehouse N-Identical Retailer Distribution System,” Management Science, Vol. 31, No. 4, 1985, pp. 488-498.

[4] L. Lu, "A One-Vendor Multi-Buyer Integrated Inventory Model,” European Journal of Operational Research, Vol. 81, No. 2, 1995, pp. 312-323.

[5] R. A. Sarker and L. R. Khan, "Optimal Batch Size for a Production System Operating under Periodic Delivery Policy," Computers and Industrial Engineering, Vol. 37, No. 4, 1999, pp. 711-730.

[6] S. Viswanathan and R. Piplani, "Coordinating Supply Chain Inventories through Common Replenishment Epochs," European Journal of Operational Research, Vol. 129, No. 2, 2001, pp. 277-286.

[7] M. Eben-Chaime, "The Effect of Discreteness in VendorBuyer Relationships,” IIE Transactions, Vol. 36, No. 6, 2004, pp. 583-589.

[8] R. M. Hill and M. Omar, "Another Look at the SingleVendor Single-Buyer Integrated Production-Inventory Problem," International Journal of Production Research, Vol. 44, No. 4, 2006, pp. 791-800.

[9] Y.-S. P. Chiu, S. W. Chiu, C.-Y. Li, and C.-K. Ting, "Incorporating Multi-Delivery Policy and Quality Assurance into Economic Production Lot Size Problem,” Journal of
Scientific \& Industrial Research, Vol. 68, No. 6, 2009, pp. 505-512.

[10] M. J. Rosenblatt and H. L. Lee, "Economic Production Cycles with Imperfect Production Processes," IIE Transactions, Vol. 18, No. 1, 1986, pp. 48-55.

[11] K. Moinzadeh and P. Aggarwal, "Analysis of a Production/Inventory System Subject to Random Disruptions," Management Science, Vol. 43, No. 11, 1997, pp. $1577-$ 1588.

[12] A. Chelbi and N. Rezg, "Analysis of a Production/InVentory System with Randomly Failing Production Unit Subjected to a Minimum Required Availability Level," International Journal of Production Economics, Vol. 99, 2006, pp. 131-143.

[13] S. W. Chiu, Y.-S. P. Chiu and C.-C. Shih, "Determining Expedited Time and Cost of the End Product with Defective Component Parts Using Critical Path Method (CPM) and Time-Costing Method," Journal of Scientific \& Industrial Research, Vol. 65, No. 9, 2006, pp. 695-701.

[14] J. Li, D. E. Blumenfeld and S. P. Marin, "Production System Design for Quality Robustness,” IIE Transactions, Vol. 40, No. 3, 2008, pp. 162-176.

[15] K-Y. C. Yu and D. L. Bricker, “Analysis of a Markov Chain Model of a Multistage Manufacturing System with Inspection, Rejection, and Rework," IIE Transactions, Vol. 25, No. 1, 1993, pp. 109-112.

[16] A. M. M. Jamal, B. R. Sarker and S. Mondal, “Optimal Manufacturing Batch Size with Rework Process at a Single-Stage Production System," Computers \& Industrial Engineering, Vol. 47, No. 2, 2004, pp. 77-89.

[17] S. W. Chiu and Y.-S. P. Chiu, "Mathematical Modeling for Production System with Backlogging and Failure in Repair," Journal of Scientific \& Industrial Research, Vol. 65, 2006, pp. 499-506.

[18] S. W. Chiu, "Production Run Time Problem with Machine Breakdowns under AR Control Policy and Rework," Journal of Scientific \& Industrial Research, Vol. 66, No. 12, 2007, pp. 979-988

[19] S. W. Chiu, K.-K. Chen and H.-H. Chang, "Mathematical Method for Expediting Scrap-or-Rework Decision Making in EPQ Model with Failure in Repair," Mathematical and Computational Applications, Vol. 13, No. 3, 2008, pp. 137-145.

[20] S. W. Chiu, "Robust Planning in Optimization for Production System Subject to Random Machine Breakdown and Failure in Rework," Computers \& Operations Research, Vol. 37, No. 5, 2010, pp. 899-908.

[21] R. W. Grubbström and A. Erdem, "The EOQ with Backlogging Derived without Derivatives," International Journal of Production Economics, Vol. 59, No. 1-3, 1999, pp. 529-530.

[22] S. W. Chiu, "Production Lot Size Problem with Failure in Repair and Backlogging Derived without Derivatives," European Journal of Operational Research, Vol. 188, No. 2, 2008, pp. 610-615.

[23] S. W. Chiu, C.-B. Cheng, M.-F. Wu and J.-C. Yang, “An Algebraic Approach for Determining Optimal Lot Size 
for EPQ Model with Rework Process,” Mathematical and Computational Applications, Vol. 2010, No. 3, 2010, pp. 364-370.

[24] S. W. Chiu, H.-D. Lin, C.-B. Cheng and C.-L. Chung,
"Optimal Production-Shipment Decisions for the Finite Production Rate Model with Scrap," International Journal for Engineering Modelling, Vol. 22, Issues 1-4, 2009, pp. 15-24.

\section{Appendix}

Nomenclature:

$C=$ unit manufacturing cost,

$C_{\mathrm{S}}=$ the disposal cost per scrap item,

$h=$ unit holding cost,

$K=$ setup cost per production run,

$K_{1}=$ fixed delivery cost per shipment,

$C_{T}=$ unit delivery cost $C_{T}$,

$Q=$ production lot size, a decision variable, to be determined for each cycle,

$T$ = production cycle length,

$n=$ number of fixed quantity installments of the finished batch to be delivered to customers, a decision variable, to be determined for each cycle,

$d=$ production rate of scrap items,

$t_{1}=$ the production uptime for the proposed EPQ model,

$t_{2}=$ time required for delivering all finished products,

$H=$ maximum level of on-hand inventory in units when regular production process ends,

$t_{\mathrm{n}}=$ a fixed interval of time between each installment of finished products delivered during production downtime $t_{2}$,

$I(t)=$ on-hand inventory of perfect quality items at time $t$,

$T C(Q, n)=$ total production-inventory-delivery costs per cycle for the proposed model,

$\mathrm{E}[\operatorname{TCU}(Q, n)]=$ the long-run average costs per unit time for the proposed model. 